\title{
ANALISA PREDIKSI MAHASISWA DROP OUT MENGGUNAKAN METODE DECISION TREE DENGAN ALGORITMA ID3 dan C4.5
}

\author{
Laksamana Rajendra Haidar ${ }^{1}$, Eko Sediyono ${ }^{2}$, Ade Iriani ${ }^{3}$ \\ ${ }^{1}$ Magister Sistem Informasi,Fakultas Teknologi Informasi, Universitas Kristen Satya Wacana, \\ Salatiga,email: laksamanahaidar@gmail.com \\ JIn. Dr. O. Notohamidjojo Blotongan Sidorejo, Kota Salatiga, 50715, Indonesia \\ ${ }^{2}$ Magister Sistem Informasi, Fakultas Teknologi Informasi, Universitas Kristen Satya Wacana, \\ Salatiga, email: eko@uksw.edu \\ JIn. Dr. O. Notohamidjojo Blotongan Sidorejo, Kota Salatiga, 50715, Indonesia, \\ ${ }^{3}$ Magister Sistem Informasi, Fakultas Teknologi Informasi, Universitas Kristen Satya Wacana, \\ Salatiga, email: adeiriani@uksw.edu \\ Jln. Dr. O. Notohamidjojo Blotongan Sidorejo, Kota Salatiga, 50715, Indonesia,
}

\section{ARTICLE INFO}

Article history:

Received 18 September 2019

Received in revised form 21 October 2019

Accepted 28 October 2019

Available online 31 January 2020

\section{ABSTRACT}

The case of drop out at the Weleri STEKOM is often done by the campus. Drop out is a problem that is often done by Weleri STEKOM students because of a GPA of less than 2, Number of organizations followed, Tuition not paid for students and student who have exceeded the limit of 14 semesters. This study discusses predicting drop out students with C4.5 and ID3 decision tree methods that are useful to assist the campus in anticipating student dropouts. This study uses student data as many as 1087 students. Student data is divided into training data and testing data in order to obtain a model or rule in predicting DO students. Variable of this reseach contain V1(GPA) and then V2 (Distance beetween home and campus), V3(how long the lecture has been done), V4(Having a Job), V5(Family) and V6(school fee). This research The results of this study obtained 18 rules or rules for ID3 algorithm and 8 rules for C4.5 algorithm. The algorithm ID3 test results obtained an average of $95.17 \%$, precision of $94.7 \%$ and recall of $96.18 \%$, while for Decision Tree C 4.5 obtained an average of $96.45 \%$, precision of $96.90 \%$ and recall of 95.38. This research prove that Decision using C4.5 is better for prediction of drop out students at STEKOM.

Keywords:Decision Tree, ID3, C4.5, Drop out 


\section{Pendahuluan}

Pendidikan saat ini merupakan kebutuhan yang sangat penting yang harus dilakukan oleh masyarakat sekitar. Banyak sekali masyarakat yang melanjutkan pendidikan mereka ke jenjang yang lebih lanjut yaitu memasuki Perguruan Tinggi atau Sekolah Tinggi. STEKOM adalah Perguruan Tinggi Swasta yang dibangun pada tahun 1991 oleh Bapak Dr, Ir Agus Wibowo sebagai Ketua yayasan saat itu. Dahulu STEKOM merupakan tempat kursus computer yang banyak diminati masyarakat sekitar. Kemudian tahun 1996, STEKOM berkembang menjadi Sekolah Tinggi untuk pendidikan Elektronika dan Komputer waktu itu. Seiring berjalannya waktu banyak sekali masalah-masalah yang terjadi selama proses kegiatan kampus yaitu Drop out [1]. Drop out adalah tindakan yang dilakukan oleh kampus untuk mengeluarkan mahasiswa karena perilaku yang tidak baik dan masa studi kuliah yang sudah melewati batas [2]. Masalah-masalah yang timbul pada mahasiswa drop out adalah Faktor Utama batas studi kuliah mahasiswa yang ditempuh mahasiswa maksimal sampai 14 Semester atau 7 Tahun [3]. Dinas Pendidikan sudah menegaskan aturan tersebut bahwa mahasiswa yang sudah melewati 14 semester harus segera dikeluarkan.Tidak hanya masa studi saja yang menjadi factor yang mempengaruhi drop out, Jarak dan Transportasi juga bisa berpengaruh drop out dikarenakan karena rumah terlalu jauh dari kampus dan tidak adanya transportasi menyebabkan mahasiswa menjadi malas untuk berangkat.Faktor lainnya yaitu faktor pekerjaan, Faktor biaya kuliah yang menumpuk juga mempengaruhi tingkat drop out yang tinggi karena biaya kuliah yang relatif lebih mahal sehingga mahasiswa tidak mau melunasinya [4]. Serta mayoritas mahasiswa STEKOM merupakan kelas karyawan maka pekerjaan juga mempengaruhi tingkat drop out dalam kampus STEKOM.

Tujuan dari Penelitian ini adalah dapat memprediksi tingkat mahasiswa drop out dengan menggunakan algoritma ID3 dan C4.5. Penelitian ini mengambil data mahasiswa sebanyak 1087 mahasiswa. Kemudian data tersebut akan diprepocessing terlebih dahulu sebelum diolah,apakah ada data yang salah atau tidak sesuai dengan format penulisan nya. Setelah Data Preprocessing, data dibagi menjadi Data Training dan Data untuk Pengujian (Data Testing). Untuk tingkat ketepatan atau akurasi model decision tree, maka dilakukan pengujian Data Testing dari $60 \%$ sampai 90\%. Kemudian diperoleh model tree yang digunakan untuk memprediksi apakah mahasiswa tersebut termasuk dalam kategori drop out[5] . Algoritma Pohon Keputusan ID3 atau Iterative Dichotomiser 3 (ID3) merupakan sebuah metode yang digunakan untuk membuat pohon keputusan yang telah dikembangkan oleh J. Ross Quinlan sejak tahun 1986 [6]. Algoritma pada metode ini menggunakan konsep dari entropy informasi. Algoritma ini melakukan pencarian secara rakus/menyeluruh (greedy) pada semua kemungkinan pohon keputusan[1]. Algoritma Pohon Keputusan C4.5 atau Classification version 4.5 adalah pengembangan dari algoritma ID3. Oleh karena pengembangan tersebut, algoritma C4.5 mempunyai prinsip dasar kerja yang sama dengan algoritma ID3. Perbedaan utama C4.5 dari ID3 yaitu Pemilihan atribut yang dilakukan dengan menggunakan Gain Ratio dan Hasil pohon keputusan C4.5 dipangkas setelah dibentuk [7].

\section{Metode Penelitian}

Dari gambar di bawah menunjukkan alur penelitian prediksi mahasiswa drop out yaitu langkah pertama mencari data mahasiswa dengan observasi dan meminta data mahasiswa di Kampus STEKOM dari angkatan 2013 sampai 2015, setelah itu data akan di preprocessing atau diolah supaya bisa di terapkan ke dalam tool rapidminer. Setelah itu data akan dibagi menjadi 2 bagian yaitu data training dan data testing pada masing-masing algoritma. Data diolah menggunakan tool rapid miner kemudian akan mendapatkan hasil akurasi,presisi dan recall dari pengujian data testing 50-90\% dengan menggunakan Algoritma ID3 dan C4.5. Langkah bisa dilihat pada gambar 1.

TRANSFORMATIKA Vol. 17, No. 2, January 2020 : 97-106 


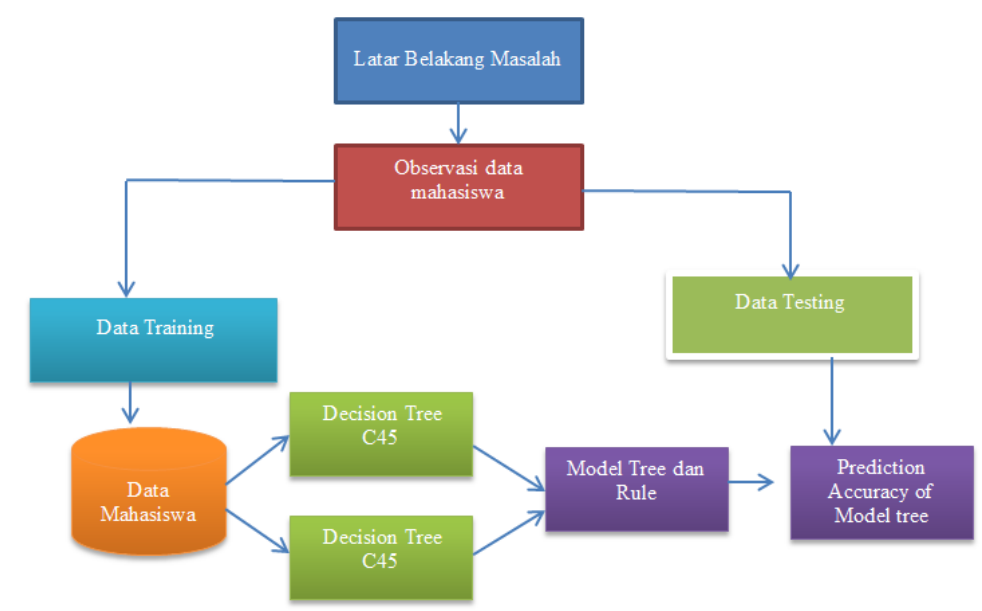

Gambar 1. Tahap Penelitian Prediksi Mahasiswa Drop Out

Data mahasiswa yang didapatkan dari proses pengumpulan data sebanyak 1087 record dan memiliki 6 atribut. Setelah data didapatkan untuk melakukan penelitian maka ada beberapa tahapan preparation data. Preparation data merupakan tahap-tahap untuk menghasilkan data yang mempunyai informasi yang produktif, maka dapat dilakukan beberapa teknik sebagai berikut:

a. Data Cleaning

Data yang berkualitas sangat mempengaruhi kualitas keputusan yang diperoleh. Data yang tidak berkualitas adalah data yang nilai atributnya hilang, error dan data yang tidak konsiten dalam pengisian atributnya. Untuk mendapatkan datayang berkualitas dilakukan tahapan dalam data Cleaning sebagai berikut :Menghilangkan data yang tidak lengkap terdapat 4 data dari 1091 record yang tergolong sangat tidak lengkap,sehingga data yang dapat digunakan menjadi 1087 record[8].

b. Data Integration and Transformation

Teknik yang digunakan untuk menganalisis data kolerasi,atribut yang redundan disebut integration,sedangkan transformation berguna untuk meningkatkan akurasi dan efisiensi Algoritma ID3 dan C4.5 memiliki kelebihan memproses data yang bernilai nominal,ortodinal maupun kontinyu.Sehingga nilai - nilai setiap atribut yang terdapat pada dataset tidak perlu ditransformasikan [9].

c. Data Reduction

Dataset dapat direduksi dengan mengurangi jumlah atribut dan record supaya menjadi lebih sedikit tetapi tetap bersifat informatif[8]. Dengan memperoleh representasi dalam bentuk volume data yang telah berkurang jumlahnya namun tetap mendapatkan hasil analisis yang sama. Deskretasi data merupakan bagian dari reduksi data bagian penting untuk data numerik. Berikut adalah keseluruhan variabel sesudah dilakukan reduction data pada tabel 1 .

\begin{tabular}{c|l}
\multicolumn{2}{c}{ Tabel 1 Nama Variable Yang Digunakan } \\
\hline Ko & \multicolumn{1}{|c}{ NamaVariable/atribut } \\
\hline V1 & IPK \\
\hline V2 & Jarak Rumah ke kampus(Km) \\
\hline V3 & Lama Kuliah(SMT) \\
\hline V4 & Memiliki Pekerjaan \\
\hline V5 & Memiliki Keluarga \\
\hline V6 & Lunas Biaya Kuliah \\
\hline
\end{tabular}

Berikut ini merupakan data mahasiswa STEKOM sebanyak 1087 data, dimana data ini merupakan data privat yang ada di kampus STEKOM. Kriteria yang digunakan yaitu IPK (Indeks

Analisis Prediksi Mahasiswa Drop Out Menggunakan Metode Decision Tree dengan Algoritma ID3 dan C4.5 (Laksamana Rajendra Haidar) 
Prestasi Komulatif), Jarak rumah ke kampus, lama Kuliah, Pekerjaan, Keluarga dan Tagihan Pembayaran Kuliah. Kriteria ini dirubah menjadi kategori agar mempermudah dalam pengolahan data.Data Mahasiswa STEKOM bisa lihat di Tabel 2.

Dibawah ini merupakan Data Mahasiswa STEKOM Angkatan 2013-2015, Data ini didapat melalui studi literature pada Kampus STEKOM.

Tabel 2 Data Mahasiswa Stekom Angkatan 2013-2015

\begin{tabular}{c|l|c|c|c|c}
\hline No & \multicolumn{1}{|c}{ Mahasiswa } & V1 & V2 & V5 & V6 \\
\hline 1 & Ningsih Triyanti & 3,25 & 17 & $\ldots \ldots$ & Lunas \\
\hline 2 & Nur Hidayah & 3 & 10 & $\ldots \ldots$ & Lunas \\
\hline 3 & Inggar Santiari Pangestu & 3,2 & 12 & $\ldots \ldots$ & Lunas \\
\hline 4 & Wahyu Ariana & 3,8 & 2 & $\ldots \ldots$ & Lunas \\
\hline 5 & Wahyu Ariani & 3,6 & 5 & $\ldots \ldots$ & Lunas \\
\hline & & $\ldots \ldots$ & $\ldots \ldots$ & & $\ldots \ldots$ \\
\hline 1087 & Nia Puspita Dewi & 3,6 & 5 & $\ldots \ldots$ & Lunas \\
\hline
\end{tabular}

Langkah Metode Decision Tree ID3:

Menghitung Nilai Entropi dan Information Gain dari Setiap Variable dengan menggunakan rumus yang ada dibawah ini[10].

$$
\operatorname{Entropy}(S)=-D_{+} \log _{2} D_{+}-D_{-} \log _{2} D_{-}
$$

Catatan:

$S$ :sampel data yang digunakan dalam training.

$D_{+}$: Jumlah Data yang mendukung(positif) terhadap data sample untuk variable tertentu.

$D_{-}$: Jumlah Data yang tidak mendukung(negative)terhadap data sample untuk variable tertentu.

Untuk Perhitungan Gain bisa dilihat menggunakan rumus dibawah ini:

Catatan:

$$
\operatorname{Gain}(S, V)=\operatorname{Entropy}(S)-\sum_{k \text { nilai }} \frac{\left|S_{k}\right|}{|S|} \operatorname{Entropy}\left(S_{k}\right)
$$

S: sampel data yang digunakan dalam training

$\mathrm{V}$ : variable

$\mathrm{K}$ : nilai yang mungkin terhadap nilai $V$

$\left|S_{k}\right|:$ Jumlah data sampel yang mempunyai nilai $k$

$|S|$ : Jumlah semua data sampel

Tujuan dari perhitungan Gain adalah menjadi varibel mana yang kan dijadikan node awal dengan nilai Information Gain yang paling besar membuat dengan nilai gain paling tinggi setelah itu $\mathrm{m}$ embuat lanjutan note dengan kriteria yang lain[11].

Setelah itu lakukan split validation untuk menguji tingkat akurasi antara data testing dan data training. Split Validation adalah proses pembagian seluruh data menjadi 2 bagian yaitu data training dan data testing[5]. Pada Penelitian ini dilakukan split validation dari 50\% sampai dengan $90 \%$ data training dari masing-masing algoritma C4.5 dan ID3

\section{Hasil dan Analisa}

Dibawah ini merupakan contoh perhitungan manual dari penerapan algoritma ID3 memprediksi mahasiswa drop out dengan menggunakan 652 data training atau data training sebesar 50\%. Pada Algoritma ID3 harus menentukan pohon keputusan yang kemudian menjadi rule mengetahui mahasiswa drop out.

TRANSFORMATIKA Vol. 17, No. 2, January 2020 : 97-106 
Tabel 3 Perhitungan Node Awal Pada Algoritma ID3

\begin{tabular}{c|c|c|c|c|c|c}
\hline Variable & & $\begin{array}{c}\text { Jumlah } \\
\text { Kasus }\end{array}$ & B & S & DO & $\begin{array}{c}\text { Information } \\
\text { Gain(IG) }\end{array}$ \\
\hline & & 1088 & & & & \\
\hline V1 & & & & & & 0,16 \\
\hline & High & 120 & 63 & 57 & 0 & \\
\hline & Normal & 51 & 0 & 44 & 7 & \\
\hline V2 & Low & 29 & 0 & 0 & 29 & \\
\hline & Far & 49 & 15 & 26 & 8 & \\
\hline & Near & 151 & 48 & 75 & 28 & \\
\hline V3 & & & & & & 0,72302 \\
\hline & On & 64 & 63 & 1 & 0 & \\
\hline & Time & & & & & \\
\hline V4 & Late & 136 & 0 & 100 & 36 & \\
\hline & Yes & 72 & 39 & 14 & 19 & \\
\hline & No & 128 & 24 & 87 & 17 & \\
\hline V5 & & & & & & 0,23 \\
\hline & Yes & 72 & 39 & 14 & 19 & \\
\hline & No & 128 & 24 & 87 & 17 & \\
\hline V6 & & & & & & 0,12 \\
\hline & Not & 54 & 8 & 10 & 36 & \\
\hline & Paid & 146 & 55 & 91 & 0 & \\
\hline & Off & & & & & \\
\hline
\end{tabular}

Dari tabel 3 menunjukkan bahwa data mahasiswa diatas dapat dihitung menggunakan algoritma ID3 dan memperoleh nilai entropi total serta Information Gain. Nilai Information Gain yang terbesar menjadi root awal atau node awal dari pembentukan model decision tree [12]. Hasilnya menunjukkan bahwa Gain terbesar terletak pada variable V3 (Lama Kuliah) yaitu sebesar 0,72. Oleh karena itu Variable Lama Kuliah dijadikan sebagai node awal. Setelah itu diulangi proses diatas sampai semua variabel menjadi node, sehingga perlu dilakukan perhitungan lebih lanjut.Untuk mempermudah proses analisa dibutuhkan software rapidminer agar lebih cepat dan akurat. Setelah data diolah menggunakan Software rapidminer maka diperoleh model tree dari masing-masing algoritma ID3 dan C4.5. Untuk model tree bisa dilihat pada gambar 2 untuk model tree ID3 dan gambar 3 untuk model tree algoritma C4.5[13] . 


\subsection{Hasil Algoritma ID3}

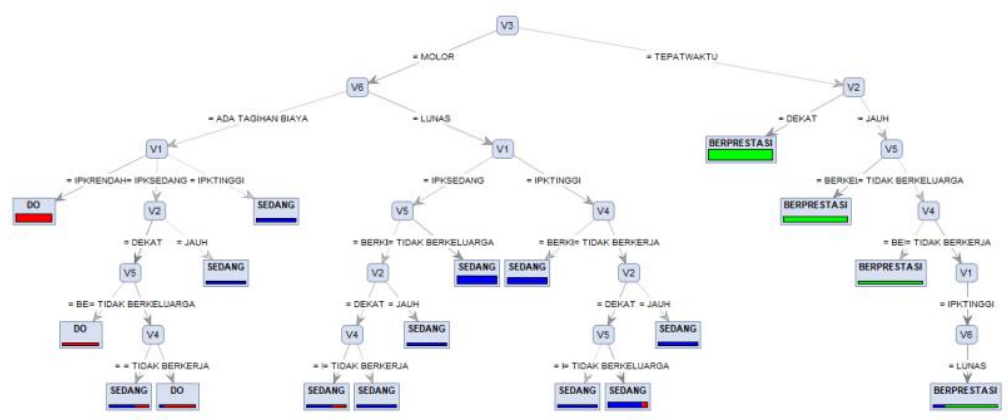

Gambar 2 Model Tree menggunakan Algoritma Decision Tree ID3

Pada gambar 2 bisa dilihat dari hasil pengolahan menggunakan tool Rapid miner, dengan menggunakan algoritma ID3 pohon keputusan dengan 18 rule atau aturan dengan menggunakan data sebanyak 1087 data[9].

Tabel 4 Rule Prediksi Algoritma ID3

\begin{tabular}{|c|c|}
\hline Aturan & Deskripsi \\
\hline Rule 1 & $\begin{array}{l}\text { If V3 ="Molor" And V6="Ada Tagihan Biaya" And V1= "Ipkrendah" Then } \\
\text { Mahasiswa Itu DO }\end{array}$ \\
\hline Rule 2 & $\begin{array}{l}\text { If V3 ="Molor" And V6="Ada Tagihan Biaya" And V1= "Ipktinggi" Then } \\
\text { Mahasiswa Itu Sedang }\end{array}$ \\
\hline Rule 3 & $\begin{array}{l}\text { If V3="Molor" And V6="Ada Tagihan Biaya" And V1= "Ipksedang" And } \\
\text { V2="Jauh" Then Mahasiswa Itu Sedang }\end{array}$ \\
\hline Rule 4 & $\begin{array}{l}\text { If V3="Molor" And V6="Ada Tagihan Biaya" And V1= "Ipksedang" And } \\
\text { V2="Dekat" And V5="Berkeluarga" Then Mahasiswa Itu DO }\end{array}$ \\
\hline Rule 5 & $\begin{array}{l}\text { If V3 ="Molor" And V6="Ada Tagihan Biaya" And V1= "Ipksedang" And } \\
\text { V2="Dekat" And V5="Tidakberkeluarga" V4="Tidak Bekerja" Then Mahasiswa } \\
\text { Itu Sedang }\end{array}$ \\
\hline Rule 6 & $\begin{array}{l}\text { If V3 ="Molor" And V6="Ada Tagihan Biaya" And V1= "Ipk sedang" And } \\
\text { V2="Dekat" And V5="Tidakberkeluarga" V4="Bekerja" Then Mahasiswa Itu DO }\end{array}$ \\
\hline Rule 7 & $\begin{array}{l}\text { If V3 ="Molor" And V6="Lunas" And V1= "Ipk sedang" And } \\
\text { V5="Tidakberkeluarga" Then Mahasiswa Itu Sedang }\end{array}$ \\
\hline Rule 8 & $\begin{array}{l}\text { If V3 ="Molor" And V6="Lunas" And V1= "Ipk sedang" And V4="Bekerja” Then } \\
\text { Mahasiswa Itu Sedang }\end{array}$ \\
\hline Rule 9 & $\begin{array}{l}\text { If V3 ="Molor" And V6="Lunas" And V1= "Ipksedang" And V5="Berkeluarga" } \\
\text { And V2="Jauh" Then Mahasiswa Itu Sedang }\end{array}$ \\
\hline Rule 10 & $\begin{array}{l}\text { If V3 ="Molor" And V6="Lunas" And V1= "Ipksedang" And V4="Tidakbekerja" } \\
\text { And V2="Jauh" Then Mahasiswa Itu Sedang }\end{array}$ \\
\hline Rule 11 & $\begin{array}{l}\text { If V3 ="Molor" And V6="Lunas" And V1= "Ipksedang" And V5="Berkeluarga" } \\
\text { And V2="Dekat" And V4="Bekerja" Then Mahasiswa Itu Sedang }\end{array}$ \\
\hline Rule 12 & $\begin{array}{l}\text { If V3 ="Molor" And V6="Lunas" And V1= "Ipksedang" And V5="Berkeluarga" } \\
\text { And V2="Dekat" And V4="Tidakbekerja" Then Mahasiswa Itu Sedang }\end{array}$ \\
\hline Rule 13 & $\begin{array}{l}\text { If V3 ="Molor" And V6="Lunas" And V1= "Ipksedang" And V4="Tidakbekerja" } \\
\text { And V2="Dekat" V5="Tidakberkeluarga" Then Mahasiswa Itu Sedang }\end{array}$ \\
\hline Rule 14 & $\begin{array}{l}\text { If V3 ="Molor" And V6="Lunas" And V1= "Ipksedang" And V4="Tidakbekerja" } \\
\text { And V2="Dekat" V5="Berkeluarga" Then Mahasiswa Itu Sedang }\end{array}$ \\
\hline Rule 15 & If V3 ="Tepat" And V2="Dekat" Then Mahasiswa Itu Berprestasi \\
\hline
\end{tabular}

TRANSFORMATIKA Vol. 17, No. 2, January 2020 : 97-106 


\begin{tabular}{l|l}
\hline Rule 16 & $\begin{array}{l}\text { If V3 ="Tepat" And V2="Jauh" And V5="Berkeluarga" Then Mahasiswa Itu } \\
\text { Berprestasi }\end{array}$ \\
\hline Rule 17 & $\begin{array}{l}\text { If V3 ="Tepat" And V2="Jauh" And V5="Tidakberkeluarga" And V4="Bekerja" } \\
\text { Then Mahasiswa Itu Berprestasi }\end{array}$ \\
\hline Rule 18 & $\begin{array}{l}\text { If V3 ="Tepat" And V2="Jauh" And V5="Tidakberkeluarga" And } \\
\text { V4="Bekerja"And V1="Ipktinggi" And V6="Lunas" Then Mahasiswa Itu } \\
\text { Berprestasi }\end{array}$ \\
\hline
\end{tabular}

Dari Tabel 4 untuk hasil pengolahan data mahasiswa angkatan 2013 sampai 2015 menggunakan tool Rapid miner ,dengan menggunakan algoritma ID3 mendapatkan 18 rule atau aturan dengan menggunakan data sebanyak 1087 data [9].

\subsection{Hasil Algoritma C4.5}

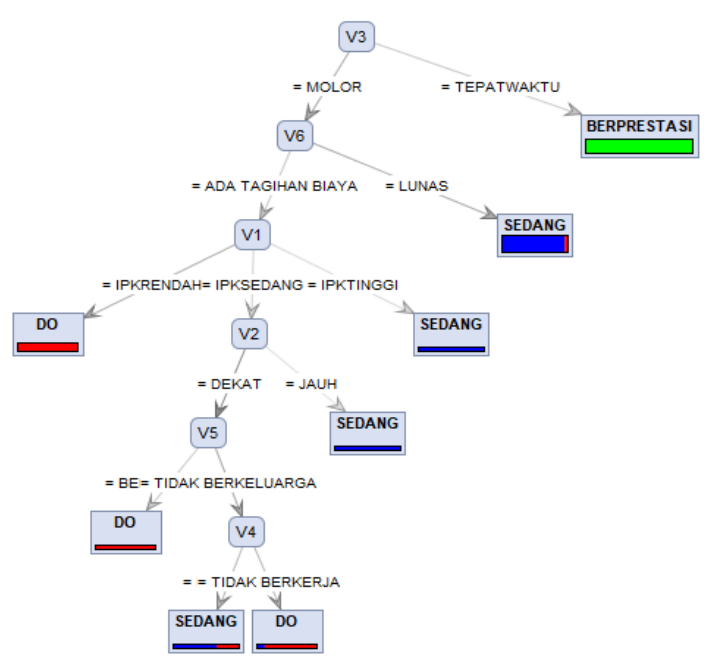

Gambar 3 Model Tree menggunakan Algoritma Decision Tree C4.5

Sedangkan pada gambar 3 bisa dilihat dari hasil pengolahan menggunakan tool Rapid minerdengan menggunakan algoritma $\mathrm{C} 4.5$ mendapatkan pohon keputusan dengan mendapatkan 8 rule. Untuk rule $\mathrm{C} 4.5$ bisa dilihat pada tabel 5

Tabel 5 Rule Prediksi Algoritma C4.5

\begin{tabular}{l|l}
\hline \multicolumn{1}{c|}{ Aturan } & \multicolumn{1}{c}{ Deskripsi } \\
\hline Rule 1 & If V3 ="Tepat Waktu" Then Mahasiswa Itu Berprestasi \\
\hline Rule 2 & If V3 ="Molor" Then And V6="Lunas" Then Mahasiswa Itu Sedang \\
\hline Rule 3 & $\begin{array}{l}\text { If V3 ="Molor" Then And V6= "Terdapat Tagihan" And V1 ="'Ipk Rendah" Then } \\
\text { Mahasiswa Itu DO }\end{array}$ \\
\hline Rule 4 & $\begin{array}{l}\text { If V3 ="Molor" Then And V6= "Terdapat Tagihan" And V1 ="'Ipk Tinggi" Then } \\
\text { Mahasiswa Itu Sedang }\end{array}$ \\
\hline Rule 5 & $\begin{array}{l}\text { If V3 ="Molor" Then And V6= "Terdapat Tagihan" And V1 ="'Ipk Sedang" And } \\
\text { V2="Jauh" Then Mahasiswa Itu Sedang }\end{array}$ \\
\hline Rule 6 & $\begin{array}{l}\text { If V3 ="Molor" Then And V6="Terdapat Tagihan" And V1 ="'Ipk Sedang" And } \\
\text { V2="Dekat" V5="Punya Keluarga" Then Mahasiswa Itu DO }\end{array}$ \\
\hline
\end{tabular}

Analisis Prediksi Mahasiswa Drop Out Menggunakan Metode Decision Tree dengan Algoritma ID3 dan C4.5 (Laksamana Rajendra Haidar) 


\begin{tabular}{l|l}
\hline Rule 7 & If V3 ="Molor" THEN AND V6= "Terdapat Tagihan" AND V1 ="IPK Sedang" \\
& AND V2="Dekat" V5="Tidak Berkeluarga" AND V4= "Tidak Punya \\
& Pekerjaan"THEN Mahasiswa ITU Sedang \\
\hline Rule 8 & If V3 ="Molor" THEN AND V6="Terdapat Tagihan" AND V1 ="IPK Sedang" \\
& AND V2="Dekat" V5="Tidak Berkeluarga" AND V4= "Tidak Punya \\
& Pekerjaan"THEN Mahasiswa ITU DO
\end{tabular}

pada tabel 5 untuk hasil Pengolahan data mahasiswa angkatan 2013 sampai 2015 menggunakan tool Rapid miner,dengan menggunakan algoritma C4.5 mendapatkan 8 rule atau aturan dengan menggunakan data sebanyak 1087 data.

\subsection{Hasil Akurasi,Recall dan Presisi (ID3 dan C4.5)}

Setelah dilakukan Model Tree dan Rule dari Software Rapid Miner [14], maka diperlukan hasil akurasi,presisi dan recall untuk masing-masing algoritma dari data training 50\% sampai data training 90\%. Hasil akurasi,presisi dan recall bisa dilihat pada gambar 4 dan gambar 5 .

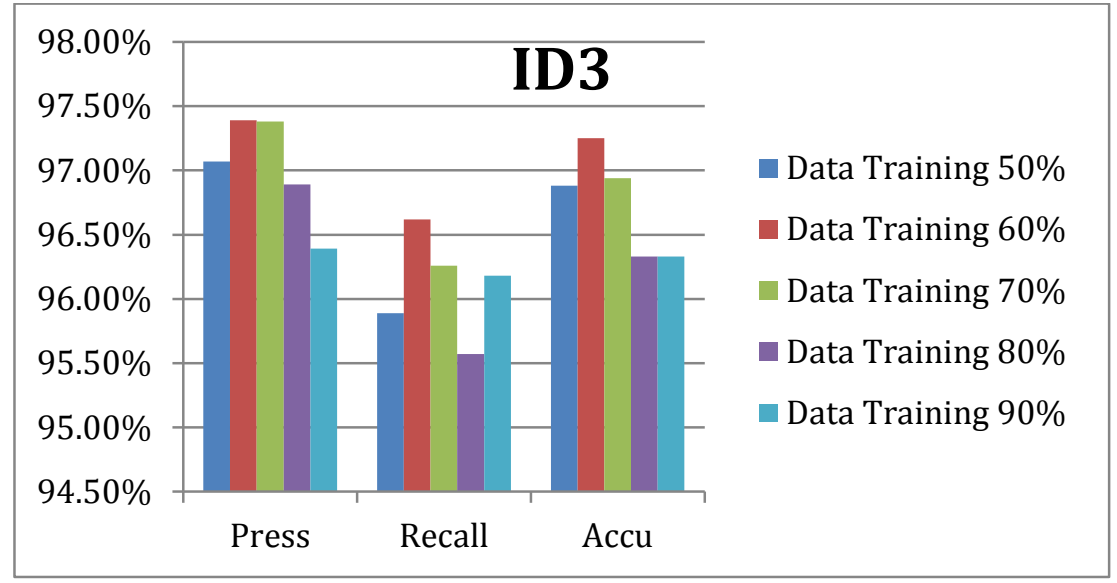

Gambar 4 Hasil Accuracy,Precision Dan Recall Metode Dengan Algoritma ID3

Dari Gambar 4 dapat disimpulkan bahwa Hasil data pengujian menggunakan algoritma ID3 didapatkan rata -rata akurasi sebesar 95,17\%, presisi sebesar 94,7\% dan recall sebesar 96,18\%.

TRANSFORMATIKA Vol. 17, No. 2, January 2020: $97-106$ 


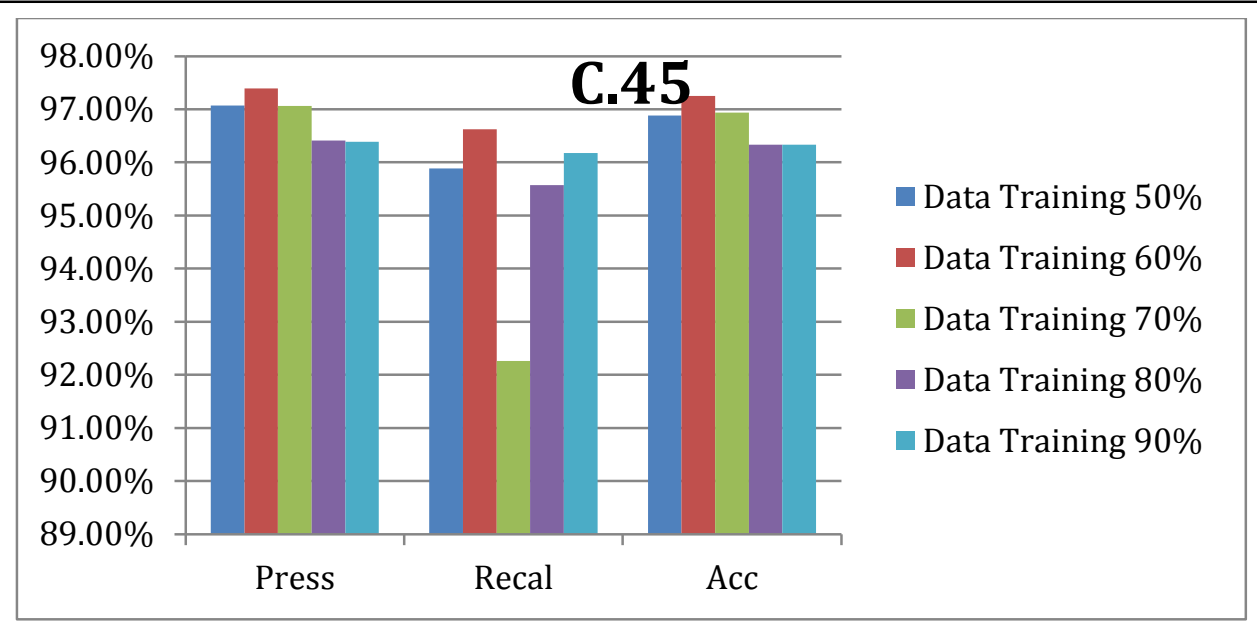

Gambar 5 Hasil accuracy, precision Dan recall metode dengan Algoritma C4.5

Dari Gambar 5 diatas dapat disimpulkan bahwa hasil data pengujian menggunakan algoritma C4.5 didapatkan rata -rata akurasi sebesar 96,45\%,presisi sebesar 96,90\% dan recall sebesar $95,38 \%$

Dari hasil pengukran tingkat akurasi, presisi dan recall diatas bahwa model Tree tersebut dapat digunakan sebagai acuan prediksi untuk mahasiswa generasi selanjutnya dan bisa sebagai referensi agar mahasiswa tidak mendapatkan drop out. Pengukuran Terbaik yaitu menggunakan model tree dengan Algoritma C4.5.

\section{Kesimpulan}

Dari hasil Penelitian diatas dapat memdapatkan kesimpulan yaitu :

1.Hasil Klasifikasi menggunakan metode Algoritma Decision Tree ID3 didapatkan sebanyak 18 rule/aturan.

2.Hasil Klasifikasi menggunakan metode Algoritma Decision Tree C 45 diperoleh model tree dan rule sebanyak 8 rule/aturan

3.Untuk hasil pengukuran Akurasi dengan menggunakan ID3 diperoleh rata-rata 95,17\%,presisi sebesar 94,7\% dan recall sebesar 96,18\%. Sedangkan algoritma Decision Tree C 45 diperoleh ratarata akurasi presisi dan recall sebesar 96,45\%,presisi sebesar 96,90\% dan recall sebesar 95,38.

\section{Referensi}

[1] R. Indriati, M. Kom, R. Firliana, M. Kom, And S. Informasi, “Artikel Prediksi Mahasiswa Drop Out Berdasarkan Klasifikasi Administratif Oleh : Inggit Hasta Wijaya Dibimbing Oleh : Surat Pernyataan Artikel Skripsi Tahun 2017,” Vol. 02, No. 01, 2018.

[2] S. Nurhayati, E. T. Luthfi, And U. Y. Papua, "Prediksi Mahasiswa Drop Out Menggunakan Metode Support Vector," Vol. X, No. X, Pp. 82-93, 1978.

[3] J. Dinamika, V. Teknik, J. Pendidikan, T. Mesin, F. Teknik, And U. N. Yogyakarta, "Faktor Penghambat Studi Mahasiswa Yang Tidak Lulus Tepat Waktu Di Jurusan Pendidikan Teknik Mesin Ft Uny," Vol. 2, Pp. 127-138, 2017.

[4] A. Iriani, "Penerapan Knowledge Management Pada Perguruan Tinggi ( Studi Kasus : Bagian Administrasi Perguruan Tinggi X ),” Pp. 45-48.

[5] N. El, I. Karabadji, H. Seridi, F. Bousetouane, W. Dhifli, And S. Aridhi, “An Evolutionary Scheme

Analisis Prediksi Mahasiswa Drop Out Menggunakan Metode Decision Tree dengan Algoritma ID3 dan C4.5 (Laksamana Rajendra Haidar) 
For Decision Tree Construction," Knowledge-Based Syst., 2016.

[6] S. Kasus, D. I. Sma, And N. Rembang, Decision Tree Id3 Untuk Rekomendasi Pemberian Beasiswa Di Sekolah. 2016.

[7] P. Algoritma And C. Untuk, "Penerapan Algoritma C4.5 Untuk Prediksi Penggunaan Jenis Kontrasepsi Berbasis Web,” Vol. 04, No. 02, Pp. 174-187, 2017.

[8] A. Rajaraman And J. D. Ullman, “Mining Of Massive Datasets,” 2011.

[9] “Data Mining Using Rapidminer By William Murakami-Brundage Mar. 15, 2012,” 2012.

[10] J. Adiana, E. Sediyono, And O. Dwi, "Pendekatan Metode Pohon Keputusan Menggunakan Algoritma Id3 Untuk Sistem Informasi Pengukuran Kinerja Pns,” Vol. 02, Pp. 75-86, 2014.

[11] I. R. Munthe And V. Sihombing, "Klasifikasi Algoritma Iterative Dichotomizer ( Id3 ) Untuk Tingkat Kepuasan Pada Sarana Laboratorium Komputer,”Vol. 1, Pp. 27-34, 2018.

[12] J. Teknologi And U. Mulawarman, "Penerapan Algoritma Id3 Decision Tree Pada Penentuan Penerima Program Bantuan Pemerintah Daerah Di Kabupaten Kutai Kartanegara,” Vol. 2, No. 2 , 2018.

[13] U. Guide, O. Reference, And D. Tutorial, "Rapidminer 4.4."

[14] K. Discovery, G. Ertek, And D. Tapucu, Text Mining With Rapidminer. 2013.

TRANSFORMATIKA Vol. 17, No. 2, January 2020:97-106 